\title{
ECKART, Wolfgang U., JÜTTE, Robert, Das europäische Gesundheitssystem. Gemeinsamkeiten und Unterschiede in historischer Perspektive
}

Isabelle von Bueltzingsloewen

\section{(2) OpenEdition}

Édition électronique

URL : http://journals.openedition.org/ifha/1953

DOI : $10.4000 /$ ifha. 1953

ISSN : 2198-8943

Éditeur

IFRA - Institut franco-allemand (sciences historiques et sociales)

Référence électronique

Isabelle von Bueltzingsloewen, « ECKART, Wolfgang U., JÜTTE, Robert, Das europäische Gesundheitssystem. Gemeinsamkeiten und Unterschiede in historischer Perspektive », Revue de I'IFHA [En ligne], Date de recension, mis en ligne le 01 janvier 1995, consulté le 22 septembre 2020. URL : http:// journals.openedition.org/ifha/1953; DOI : https://doi.org/10.4000/ifha.1953

Ce document a été généré automatiquement le 22 septembre 2020.

(CIFHA 


\title{
ECKART, Wolfgang U., JÜTTE, Robert, Das europäische
} Gesundheitssystem. Gemeinsamkeiten und Unterschiede in historischer Perspektive

\author{
Isabelle von Bueltzingsloewen
}

1 Cet ouvrage publié par l'Institut d'Histoire de la Médecine de la Fondation Robert Bosch (Stuttgart), est le résultat d'une démarche résolument comparatiste, dont il faut souligner l'originalité dans l'état actuel d'une histoire de la santé qui privilégie toujours les approches nationales alors même que dans de nombreux autres domaines l'histoire comparée, stimulée par la construction européenne, connaît un essor prometteur.

2 Le constat de départ, posé par R. JÜTTE dans une introduction tout à fait stimulante est le suivant: de nombreuses enquêtes sociologiques et ethnologiques récentes ont montré à quel point, malgré la multiplication des rencontres scientifiques et des commissions internationales, malgré la circulation des chercheurs, des enseignants et des étudiants, la médecine reste prisonnière des barrières nationales, à la fois linguistiques et culturelles et ce à l'intérieur même de l'Europe, y compris entre des pays aussi proches que la France et l'Allemagne. Encore faut-il expliquer ces contrastes et ces différences dans la culture et la pratique médicales ainsi que dans le rapport à la maladie et à la médecine des patients aussi bien que des médecins. Si l'on veut éviter de sombrer dans des clichés qui renvoient généralement à l'existence de très hypothétiques caractères nationaux, l'examen des traditions et des héritages historiques paraît indispensable et confère un rôle fondamental à l'historien de la santé, susceptible de mettre en relation les systèmes de santé et les conditions économiques, sociales et culturelles, parfois très variables selon les pays, qui ont motivé leur mise en œuvre.

3 Tel est l'objectif que se sont fixé les auteurs des six articles rassemblés dans ce recueil. Les deux premières contributions concernent la lutte contre les épidémies: celle de $\mathrm{M}$. 
DINGES prend l'exemple de la la peste et montre que face à une même menace épidémique, les mesures adoptées ont été très différentes en Italie, en Allemagne et en Angleterre, beaucoup plus précoces et strictes dans le sud que dans le nord de l'Europe. L'article de M. STOLBERG, qui compare le cas de l'Allemagne et celui de l'Italie, aboutit à des conclusions semblables pour la lutte contre le choléra au XIXe s.; il montre en particulier que les pays à régime autoritaire ont opté pour la théorie contagionniste et pour des mesures de quarantaine beaucoup plus sévères que les pays de tradition libérale, plus souvent anticontagionnistes et moins interventionnistes. L'article de R. BRÖER s'attache quant à lui à montrer, à travers l'analyse des lettres à contenu scientifique du XVIIe s., que très tôt, et en tout cas dès avant la création d'instances de communication telles que les académies, qui apparaissent à la fin du XVIIe s., ont existé des tentatives pour franchir les frontières nationales et faire circuler les idées scientifiques et que l'on peut par conséquent parler dès cette époque de formes d'internationalisation de la science comme le montre la diffusion de la découverte de Harvey concernant la circulation du sang. L'article de F. LOETZ, ambitieux dans sa thématique, analyse les contrastes qui existent dans le processus de médicalisation des sociétés française, allemande et anglaise, un processus qui s'est développé à des rythmes très différents, aussi bien pour ce qui concerne l'élaboration d'une politique de santé publique que la professionnalisation de la médecine et la constitution d'un corps médical qui impose peu à peu son monopole; très nuancées, les conclusions formulées, qui soulignent bien l'immensité des recherches encore à accomplir dans ce domaine, montrent également de façon convaincante la nécessité absolue d'une définition très rigoureuse du concept de médicalisation ainsi que les problèmes posés par ce type d'analyse qui de façon très contestable (car un nombre plus important d'hôpitaux, une densité plus forte de médecins ou de sages-femmes ou la bureaucratisation plus précoce de la santé publique sont-ils des critères suffisants pour déclarer qu'une société est plus médicalisée qu'une autre?) interprète souvent les contrastes observés en terme d'avance et de retard. Les deux derniers articles du recueil analysent l'influence de la médecine européenne sur le continent africain: celui de W.U. ECKART à travers l'étude de la diffusion autoritaire de la culture médicale allemande dans les colonies sous le Kaiserreich, celui d'A. HARNEIT-SIEVERS à travers une enquête sur la politique menée en Ouganda par l'administration coloniale anglaise dans les années vingt, une politique qui explique pour une bonne part les orientations et les blocages actuels dans la lutte contre le SIDA.

On ne peut qu'espérer que cette entreprise novatrice suscitera d'autres enquêtes sur un terrain comparatiste qui, malgré ses difficultés, s'avère d'ores et déjà très fécond.

Isabelle von BUELTZINGSLOEWEN 